\title{
Open bite malocclusion: Analysis of the underlying components
}

\author{
Mostafa M. El-Dawlatly, Mona M. Salah Fayed and Yehya A. Mostafa* \\ Department of Orthodontics and Dentofacial Orthopedics, Faculty of Oral and Dental Medicine, Cairo University, Cairo, Egypt
}

\begin{abstract}
Open bite malocclusion should not be regarded as a disease entity; instead it should be viewed as a clinical manifestation of underlying discrepancies.

Aim: The current study aimed at elucidating the underlying skeletal and dental components of open bite malocclusion, the significance of the contribution of each one, and whether certain correlations existed between them.

Material and methods: Dental and skeletal measurements were performed on lateral cephalometric radiographs and study models of 79 open bite cases. Statistical analysis of the performed measurements was undertaken.

Results: The flattened curve of Spee (73.4\%) and the proclination of the upper incisors (65.8\%) were the highest sharing dental components, and significantly higher than any of the other dental components $(\mathrm{P}=0.000)$. The steep mandibular plane angle $(72.2 \%)$ and the gonial angle $(59.9 \%)$ were the highest sharing skeletal components.

Conclusions: The flattened curve of Spee, mandibular plane angle, proclination of upper incisors and the gonial angle were the highest contributing components in open bite malocclusion cases. The analysis of open bite components could help the clinician design an individualized mechano-therapy addressing the underlying cause.
\end{abstract}

\section{Introduction}

Open bite malocclusion is one of the highly challenging orthodontic problems. The prevalence of anterior open bite ranges from $1.5 \%$ to $11 \%$ and varies between ethnic groups according to chronologic and dental ages [1]. Proffit et al. recorded a prevalence of approximately $3.5 \%$ in patients from 8 to 17 years of age [2]. From an expert orthodontist's point of view the challenging nature of open bite should not be restricted to the treatment mechanics. Instead, the clinician should be aware of the multifactorial nature of this type of malocclusion, including the components and factors that contribute to the decision making process. However, the etiology of open bite comprises a number of muscle malfunctions and abnormal habits, yet a developed Open bite malocclusion overlies a multitude of skeletal and dental discrepancies [3]. Thus, in order to yield successful treatment outcomes and decrease the chances of relapse, an open bite case should be approached through addressing its underlying components.

Most of the studies targeting the open bite problem have focused on the different treatment techniques and modalities especially the intrusion of posterior teeth $[4,5]$. With the emergence of the era of skeletal anchorage, many studies have investigated some innovative techniques concerning the issue of maxillary molars intrusion utilizing mini-plates and mini-implants [6-8]. Meanwhile, the studies analyzing the etiologic factors and the components of open bite have been scarce.

Those few studies have focused on comparing the skeletal and dento-alveolar features of certain groups; ethnic groups [9] or groups with different Angle classifications [11] associated with open bite as compared to control groups without open bite. Beane et al. [9] conducted a cephalometric comparison of black subjects, 51 with open bite and 52 without open bite, which was used to identify skeletal and dental differences between the two groups. They found that, the vertical skeletal pattern and the greater degree of dental proclination differentiated black patients with an anterior open bite from those without open bite. Arat et al. [12] divided a total of 77 anterior openbite cases visually according to the offending etiologic factor into 3 groups; skeletal, functional or combination and they found that more than half of the cases assessed as hyper-divergent were classified as functional.

Ellis and McNamara, 1984 and Ellis, McNamara and Lawrence, 1985 [9,10], divided a Class III and Class II sample respectively into 2 groups with and without open bite, and they concluded that the open bite groups had deformities in the maxillary and mandibular skeletal components. They stated that, open bite treatment is prone to failure if it didn't address the underlying deformity and that their study didn't analyze the spectrum of the skeletal and dental components of Class III open bite malocclusion.

There is an actual void in the orthodontic literature in analyzing the underlying components of open bite malocclusion. The current study didn't focus on investigating the etiological factors of open bite, it rather aimed at exploring the different skeletal and dental components

Correspondence to: Yehya A. Mostafa, Department of Orthodontics and Dentofacial Orthopedics, Faculty of Oral and Dental Medicine, Cairo University, Cairo, Egypt, Tel: 002-012-213-1934; Fax: 002-333-471-037, E-mail: mangoury@usa.net

Received: December 23, 2014; Accepted: February 07, 2015; Published: February 12, 2015 
of the resultant open bite malocclusion, their frequencies and whether certain correlations existed between those components.

\section{Materials and methods}

The sample comprised pretreatment lateral cephalograms and study models of 79 patients with open bite, selected from approximately 5500 patient records at the Outpatient Clinic of the Department of Orthodontics, Cairo University. The subjects' age ranged between 16 to 22 years, and their selection was based on the following criteria:

a) Negative overbite.

b) Complete eruption of the premolars.

c) No history of orthodontic treatment.

d) No severe craniofacial disorders.

e) No missing teeth

The following measurements were utilized in the study:

a) Cephalometric dental measurements (Table 1 and Figure 1,2).

b) Cephalometric skeletal measurements (Table 2 and Figure 2).

c) Measurements on the dental cast (Table 3).

Cephalometric and cast measurements of $10 \%$ of the sample were repeated by both the same observer and by a second observer to measure the intra- and inter-observer reliability.

\section{Statistical analysis}

a) Descriptive statistics: The mean and standard deviation of each of the dental and skeletal components of open bite malocclusion, and the percentage of contribution of each of the dental and skeletal components in open bite malocclusion was calculated.

b) Inferential statistics: Hypothesis test (paired t-test) was used to compare the significance of the contribution of each component to open bite malocclusion (Table 4).

c) Correlation analysis: Pearson correlation coefficient was used to correlate different open bite components. Concordance correlation coefficient was done to calculate intra-observer and interobserver reliability.

\section{Results}

Statistical analysis of the measurements taken showed the following results (Figures 3, 4):

The mean, standard deviation, and the percentage of contribution of the different dental and skeletal components in open bite malocclusion

a) Dental components: The flattened curve of Spee showed the highest contribution in open bite malocclusion (73.4\%) followed by the proclination of the upper incisors $(65.8 \%)$, under-eruption of the lower incisors (31.6\%), proclination of the lower incisors $(26.6 \%)$, lower incisors decreased clinical crown length (24.1\%), the decreased clinical crown length of the upper incisors $(20.3 \%)$, the under-eruption of the upper incisors (6.3\%). The least contributing factors in open bite malocclusion were the over-eruption of the upper posterior segment (1.3\%), and the over-eruption of the lower posterior segment (1.3\%) (Figure 4 and Table 5).

b) Skeletal components: The steep mandibular plane angle was found to be the most skeletal component contributing to open bite malocclusion (72.2\%) followed by the increased gonial angle(59.5\%), and the least sharing skeletal component was maxillary plane counter clock-wise rotation (38\%) (Figure 5).

The mean of "Ramus/FH" was found to be $82.06 \pm 5.14$ in open bite cases, representing the mean of the angulation of the mandibular ramus in open bite malocclusion.

Table 1. Dental cephalometric measurements.

\begin{tabular}{|c|c|}
\hline Maxillary anterior alveolar and basal height (Mx-AABH,mm) & $\begin{array}{l}\text { The distance between the mid-point of the alveolarmeatus of the maxillary central incisor and the intersectionpoint } \\
\text { between the palatal plane and the long axisof the maxillary central incisor. }\end{array}$ \\
\hline Maxillary posterior alveolar and basal height (Mx-PABH,mm) & $\begin{array}{l}\text { The perpendicular distance between the mid-point of the alveolar meatus of the maxillary first molar and the palatal } \\
\text { plane. }\end{array}$ \\
\hline The inclination of the upper incisors (U1/SN) & The angle formed between the extension of the long axis of the upper incisor and the SN plane. \\
\hline Mandibular anterior alveolar and basal height (Md-AABH, mm) & $\begin{array}{l}\text { The distance between the mid-point of thealveolar meatus of the mandibular central incisor and theintersection point } \\
\text { between the mandibular plane and thelong axis of the mandibular central incisor. }\end{array}$ \\
\hline Mandibular posterior alveolar and basal height (Md-PABH, mm.) & $\begin{array}{l}\text { The perpendicular distance between themid-point of the alveolar meatus of the mandibular firstmolar and the } \\
\text { mandibular plane }\end{array}$ \\
\hline The inclination of the lower incisors (L1/MP) & The angle formed between the extension of the long axis of the lower incisor and the mandibular plane. \\
\hline
\end{tabular}

Table 2. Skeletal cephalometric measurements.

\begin{tabular}{|l|l|}
\hline Mandibular plane angle (MndP-FH) & The angle formed between the mandibular plane and the Frankfort horizontal plane. \\
\hline Gonial angle (Ar-Go-Me) & The angle formed at the gonial area between the posterior border of the ramus and a corpus line \\
\hline Maxillary plane angle (SN-MaxP) & The angle formed between the maxillary plane and the SN plane. \\
\hline
\end{tabular}

Table 3. Dental cast measurements.

The length of the clinical crown of the upper central incisors (U1 clinical crown length).

The length of the clinical crown of the lower central incisors (L1 clinical crown length).

The curve of Spee.
The line formed between the midpoint of the cervical margin of the tooth and the midpoint of the incisal edge. The line formed between the midpoint of the cervical margin of the tooth and the midpoint of the incisal edge. The line formed between the deepest point on the lower buccal segment and a horizontal line formed between the most over-erupted lower incisor and the most over-erupted molar tooth. 


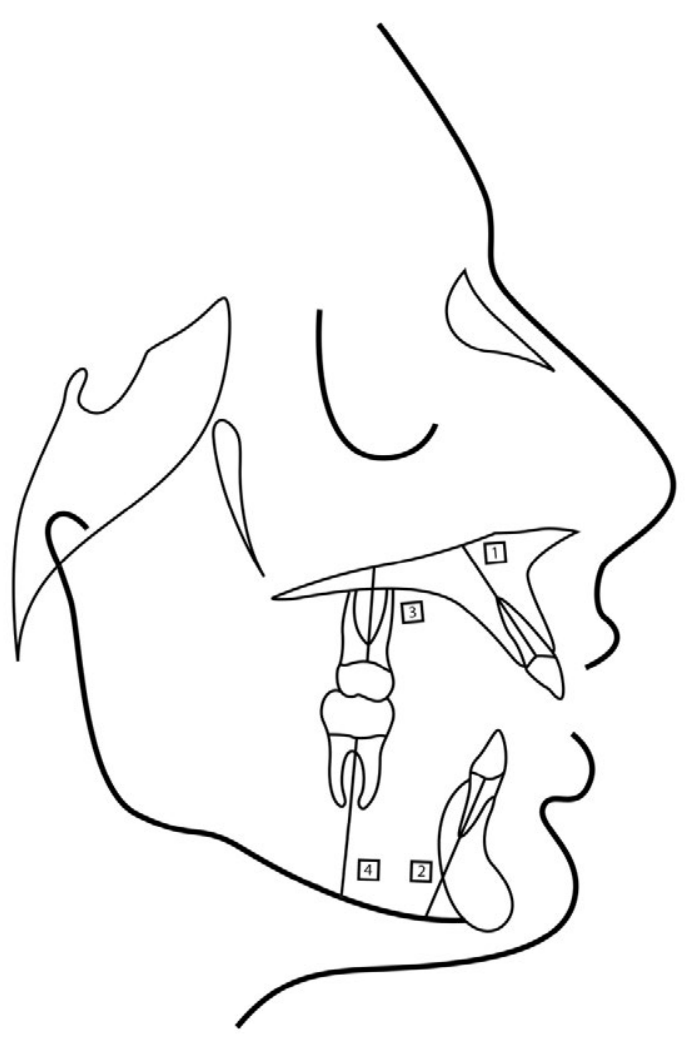

Figure 1. Dental cephalometric measurements (1-Mx-AABH, 2-Md-AABH, 3-Mx-PABH 4-Md-PABH).

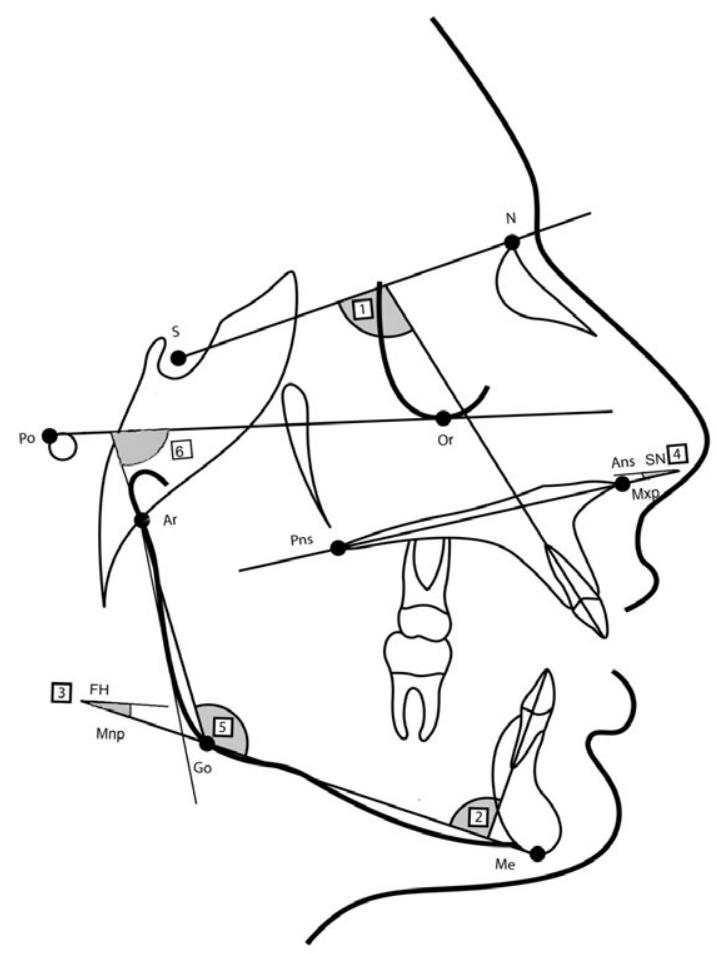

Figure 2. Dental cephalometric measurements (1-U1/SN, 2-L1/MP), and skeletal cephalometric measurements (3-FH/Mnp, 4-Mxp-SN, 5-gonial angle (Ar-Go-Me), 6-Ramus/FH).
Table 4. The significance of contribution of the skeletal components to open bite, utilizing hypothesis t-test.

\begin{tabular}{|l|c|c|c|c|}
\hline Variable & $\mathbf{\% 1}$ & $\mathbf{\% 2}$ & $\mathbf{z}$ & Probability \\
\hline mandular plane-Gonial angle & $72.2 \%$ & $59.9 \%$ & 1.677 & 0.0934 \\
\hline mandular plane-maxillary plane & $72.2 \%$ & $38.0 \%$ & 4.318 & $0.0000^{* *}$ \\
\hline Gonial angle-maxillary plane & $59.5 \%$ & $38.0 \%$ & 2.705 & $0.0068^{* *}$ \\
\hline
\end{tabular}

*Statistically significant *(P $\leq 0.05), * *(\mathrm{P} \leq 0.01)$.

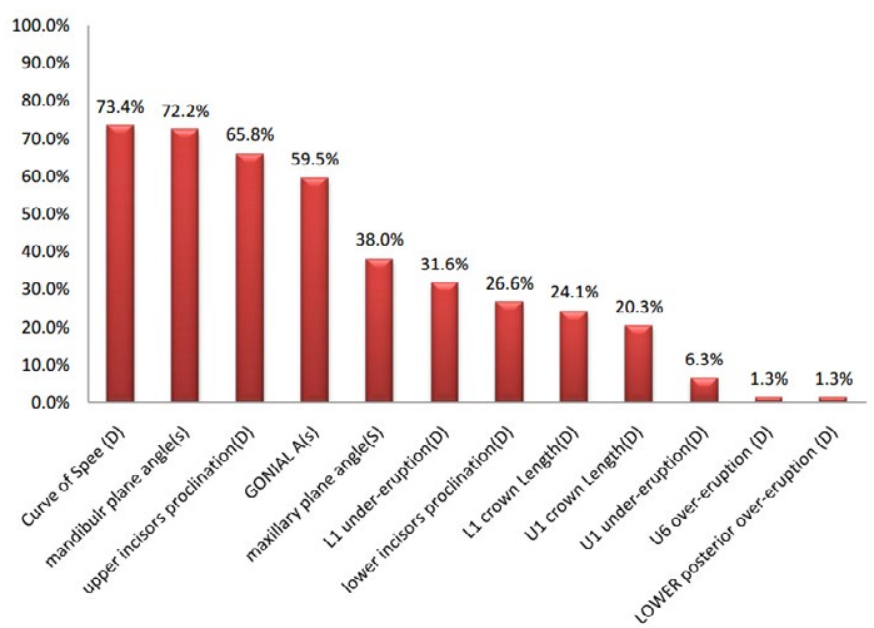

Figure 3. The Percentages of occurrence of all components in open bite malocclusion.

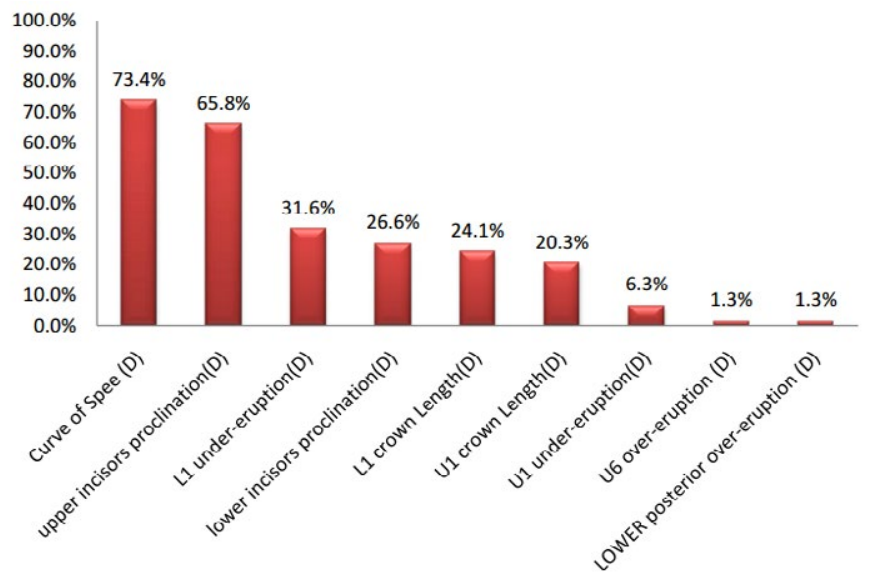

Figure 4. The percentages of occurrence of dental components in open bite malocclusion.

\section{The significance of the contribution of each of the measured components}

Regarding the contribution of the dental components (Table 5) to open bite; the flattened curve of Spee $(P=0.00000)$ and the proclination of the upper incisors $(P=0.00001)$ were significantly the highest of all the other components. The contributions of the under-eruption of the lower incisors, the lower incisors proclination and the reduced clinical crown length of the upper and lower incisors to open bite were not significant from each other. While the contributions of the previous 4 components was significantly higher from the 3 least sharing components which are the under-eruption of the upper incisors, the over-eruption of the upper posterior segment and the over-eruption of the lower posterior segment [the under-eruption of the lower incisors 
Table 5. The mean, standard deviation of the different dental and skeletal components in open bite malocclusion.

\begin{tabular}{|c|c|c|c|c|c|c|}
\hline Component & $\mathbf{N}$ & Minimum & Maximum & Mean & Std. Deviation & Coefficient of Variation \\
\hline Mandibular Plane Angle (S) & 79 & 20 & 55 & 34.43 & 7.08 & $20.6 \%$ \\
\hline Maxillary Plane Angle (S) & 79 & .0 & 15.0 & 7.72 & 3.40 & $44.1 \%$ \\
\hline GONIAL A(s) & 79 & 115 & 144 & 131.20 & 5.73 & $4.4 \%$ \\
\hline Upper Incisors Proclination (D) & 79 & 92 & 149 & 114.99 & 11.02 & $9.6 \%$ \\
\hline Lower Incisors Proclination (D) & 79 & 72 & 122 & 95.54 & 9.29 & $9.7 \%$ \\
\hline U1 under-eruption (D) & 79 & 14 & 40 & 24.97 & 4.92 & $19.7 \%$ \\
\hline L1 under-eruption (D) & 79 & 14 & 57 & 34.92 & 6.88 & $19.7 \%$ \\
\hline U6 under-eruption (D) & 79 & 11 & 30 & 20.97 & 3.77 & $18.0 \%$ \\
\hline LOWER Posterior Under-Eruption (D) & 79 & 18 & 40 & 29.10 & 4.94 & $17.0 \%$ \\
\hline Ramus/FH & 79 & 67 & 92 & 82.65 & 5.14 & $6.2 \%$ \\
\hline Curve of Spee (D) & 79 & .0 & 3.0 & 0.99 & 0.94 & $95.5 \%$ \\
\hline U1 crown Length (D) & 79 & 7.0 & 12.0 & 9.55 & 1.20 & $12.6 \%$ \\
\hline L1 crown Length (D) & 79 & 6 & 11 & 8.37 & 1.07 & $12.8 \%$ \\
\hline
\end{tabular}

Table 6. The significance of contribution of the dental components to open bite, utilizing hypothesis t-test.

\begin{tabular}{|l|c|c|c|c|}
\hline Variable & $\mathbf{\%} 1$ & $\mathbf{\% ~ 2}$ & $\mathbf{z}$ & Probability \\
\hline Curve of spee-U1 proclination & $73.4 \%$ & $65.8 \%$ & 0.768 & 0.4423 \\
\hline $\begin{array}{l}\text { Curve of Spee-L1 under-eruption and } \\
\text { smaller }\end{array}$ & $73.4 \%$ & $31.6 \%$ & 5.257 & $0.0000^{* *}$ \\
\hline $\begin{array}{l}\text { U1 proclination-L1 under-eruption and } \\
\text { smaller }\end{array}$ & $65.8 \%$ & $31.6 \%$ & 4.297 & $0.0000^{* *}$ \\
\hline L1 under-eruption-L1 proclination & $31.6 \%$ & $26.6 \%$ & 0.700 & 0.4836 \\
\hline L1 under-eruption - L1 length & $31.6 \%$ & $24.1 \%$ & 1.064 & 0.2869 \\
\hline L1 under-eruption-U1 length & $31.6 \%$ & $20.3 \%$ & 1.633 & 0.1023 \\
\hline $\begin{array}{l}\text { L1 under-eruption- U1 under-eruption } \\
\text { and smaller }\end{array}$ & $31.6 \%$ & $6.3 \%$ & 4.056 & $0.0000^{* *}$ \\
\hline L1 proclination -L1 length & $26.6 \%$ & $24.1 \%$ & 0.365 & 0.7144 \\
\hline L1 proclination-U1 length & $26.6 \%$ & $20.3 \%$ & 0.939 & 0.3475 \\
\hline $\begin{array}{l}\text { L1 proclination-U1 under-eruption and } \\
\text { smaller }\end{array}$ & $26.6 \%$ & $6.3 \%$ & 3.433 & $0.0005 * *$ \\
\hline L1 length-U1 length & $24.1 \%$ & $20.3 \%$ & 0.574 & 0.5654 \\
\hline $\begin{array}{l}\text { L1 length -U1 under-eruption and } \\
\text { smaller }\end{array}$ & $24.1 \%$ & $6.3 \%$ & 3.103 & $0.0019 * *$ \\
\hline $\begin{array}{l}\text { U1 length -U1 under-eruption and } \\
\text { smaller }\end{array}$ & $20.3 \%$ & $6.3 \%$ & 2.577 & $0.0099^{* *}$ \\
\hline $\begin{array}{l}\text { U1 under-eruption-U6 over-eruption-L6 } \\
\text { over-eruption }\end{array}$ & $6.3 \%$ & $1.3 \%$ & 1.664 & 0.0959 \\
\hline
\end{tabular}

*Statistically significant $*(\mathrm{P} \leq 0.05),{ }^{*}(\mathrm{P} \leq 0.01)$.

$(P=0.0004)$, the lower incisors proclination (0.0005), the reduced clinical crown length of the lower incisors (0.0019), and the reduced clinical crown length of the upper incisors $(P=0.0099)]$.

Considering the skeletal components (Table 6), the steep mandibular plane angle was the highest contributing with a significant difference from the counter clock-wise rotation of the maxillary plane angle $(P=0.00001)$. The gonial angle was the $2^{\text {nd }}$ skeletal sharing component with significant difference $(P=0.0068)$ from the counter clock-wise rotation of the maxillary plane angle.

\section{Correlation between different open bite components}

a) Correlation between skeletal components: The angle formed between the posterior border of the ramus and the Frankfort horizontal plane "Ramus/FH" proved to have a statistically significant weak negative correlation with the gonial angle $(P=0.016)$ (Figure 6). Meanwhile, the "Ramus/FH" had a highly statistically weak positive correlation with the mandibular plane angle $(P=0.009)$ (Figure 7$)$.

b) Correlation between dental components: There was a

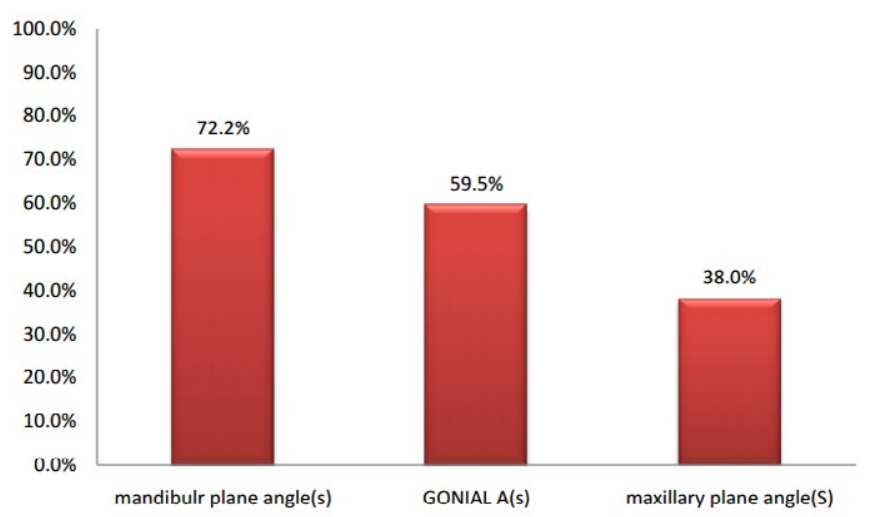

Figure 5. The percentages of occurrence of skeletal components in open bite malocclusion.

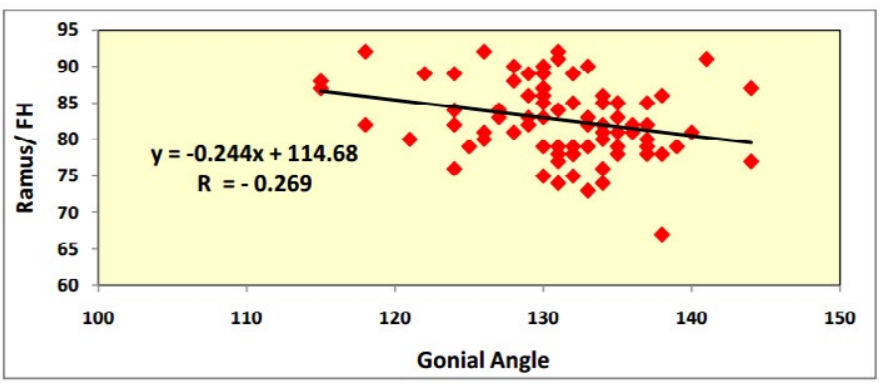

Figure 6. Correlation between "Ramus/FH" and gonial angle utilizing Pearson correlation coefficient.

highly statistically significant medium positive correlation between the under-eruption of the upper incisors and the under-eruption of the lower incisors $(P=0.000)$ (Figure 8$)$. There was also a highly statistically significant medium positive correlation between the over-eruption of the upper and the over-eruption of the lower posterior segments $(P=0.000)$ (Figure 9).

On the other hand, there was a weak positive correlation between the flattened curve of Spee and the lower incisors over-eruption $(P=0.2337)$, and between the flattened curve of Spee and the undereruption of the lower posterior segment $(P=0.2455)$. 


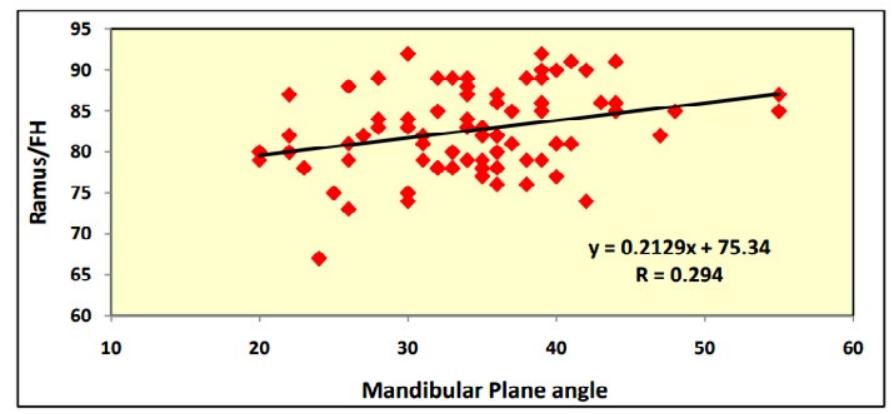

Figure 7. Correlation between "Ramus/FH" and mandibular plane angle utilizing Pearson correlation coefficient.

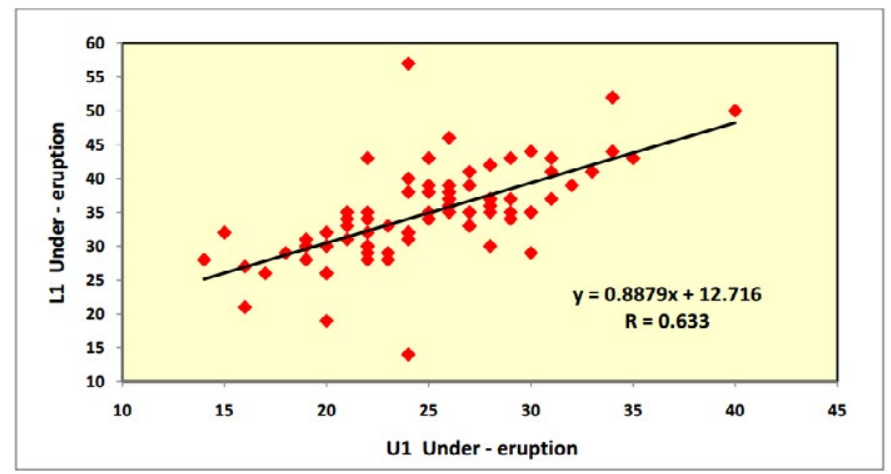

Figure 8. Correlation between "L1 under-eruption" and "U1 under-eruption" utilizing Pearson correlation coefficient.

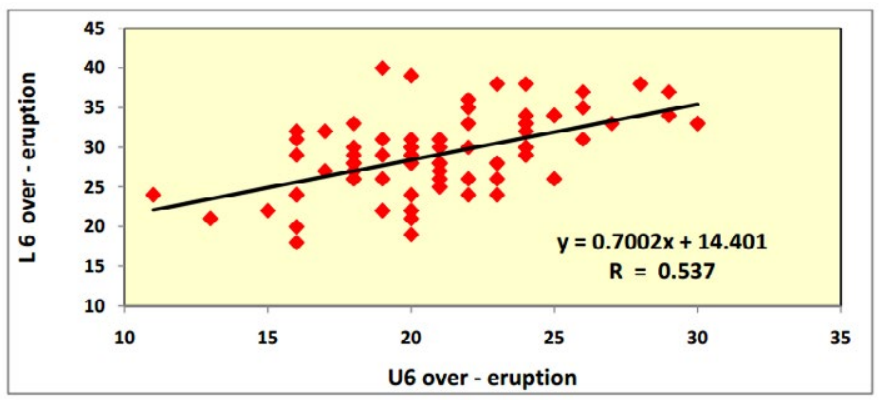

Figure 9. Correlation between "L6 over-eruption" and "U6 over-eruption" utilizing Pearson correlation coefficient.

c) Correlation between skeletal and dental components: There was no significant correlation between the gonial angle measurement and the depth of the curve of Spee or the under-eruption of the lower incisors or the over-eruption of the lower posterior segment.

\section{Inter-observer and intra-observer reliability}

High intra-observer (0.9998) and inter-observer (0.9978) reliability were found indicating reliable measurements.

\section{Discussion}

An open bite is defined as a lack of vertical overlap or contact between the upper and lower incisors in any sagittal relationship. The etiology of anterior open bite is multi-factorial. The most common causes include an unfavorable growth pattern, enlarged lymphatic tissue, digit sucking habit, unfavorable tongue and orofacial muscle activity, neurologic impairment of the control of orofacial muscle function and abnormal tongue size and posture. Open bite should not be considered as a disease entity; instead it actually represents a clinical manifestation of underlying dental and skeletal discrepancies. Studies addressing open bite malocclusion have focused on the various treatment techniques and modalities. Subsequently, the analysis of the sharing components in open bite malocclusion is still deficient.

Studies investigating the component perspective of open bite have only focused on comparing the skeletal and dental characteristics of an open bite group with a control one, overlooking the deep analysis of the sharing components in the malocclusion. Ellis, McNamara and Lawrence, 1985 [10] divided a Class II sample into 2 groups with and without open bite and they concluded that the open bite group deformity was mainly in the skeletal variables of both the mandible and the maxilla recommending the need for surgical intervention to correct the malocclusion.

On the other hand, it was found, in a sample of 77 open bite cases, that more than half of the cases which were assessed as hyper-divergent to be of a functional etiologic origin [12]. In the latter study, the authors compared an open bite sample with different Angle's classifications to a Class I control group. Although, the functional perspective is considered an important etiological factor in the development of open bite, it was not considered in the current analysis as our study aimed at elucidating the various skeletal and dental components after the development of the malocclusion using cephalometric and cast analyses, rather than exploring the origin of the vertical discrepancy. Thus, targeting to aid the clinician in the decision making process during the treatment planning phase.

From the prominent findings of the present study was that the skeletal components, whether maxillary or mandibular, have a high contribution in the developed open bite malocclusion. The higher contribution of the skeletal components in a progressing open bite implies that, the early intervention in a young age to induce orthopedic correction of the condition is beneficial. It has been proven previously that the growing open bite subjects should be treated early in the pubertal growth spurt meanwhile the late period of the pubertal spurt was suitable for the treatment of growing deep bite subjects [13].

The high contribution of both the steepness of the mandibular plane, and increased gonial angle was significantly higher than the counter-clockwise rotation of the maxilla. Accordingly, from the clinical perspective, the orthopedic modification of the mandibular growth direction and angulation early during the growth spurt should be considered; so as to redirect the growth in a more horizontal direction. The same applies for the surgical correction of severe open bites, where mandibular osteotomies are to be taken into consideration rather than altering the position and orientation of a normal maxilla.

Regarding the dental components the inclination of the upper and lower incisors [14] and the reverse curve of Spee had a significant contribution in most open bite cases. It was advocated previously that the extraction of premolars would aid in reducing the lower facial height and flattening the mandibular plane angle [15]. According to the findings of the current study, it should be stressed that the extraction mechanics in open bite treatment would aid both in normalizing the inclination of the incisors together with leveling of the lower curve of Spee.

The very low contribution of the over eruption of the upper and lower first molars elucidates the diminished need for the massive intrusion of posterior teeth in open bite treatment protocols [16]. This 
also makes the claim that open bite treatment with molar intrusion more stable questionable [17]. Since both the under-eruption of the lower incisors together with the over-eruption of the lower molars are nearly not contributing to open bite malocclusion, while the reverse curve of Spee [18] is highly contributing. Therefore, the overeruption of the premolars should be over emphasized as one of the main dento-alveolar contributing factors in the development of open bite malocclusion, raising a question whether the increased eruption of the premolars should be the logic answer for the development of the reverse curve of Spee in open bite cases. This would highlight the importance of extracting or intruding the premolars rather than the first molars in open bite extraction mechanics.

The awareness of the contributing dental and skeletal components of the open bite malocclusion, would aid the clinician in the process of treatment planning. The orthodontist would be competent to customize the treatment mechanics required for every individual open bite case. Moreover, translating the results of the current study would clarify the importance of the early treatment of open bite; overcoming the developing skeletal deformity in a growing child and modifying the extraction decisions in such cases.

\section{Conclusions}

a) The high contribution of the skeletal factors in the development of open bite malocclusion implies the necessity of early intervention to resolve the developing skeletal deformity.

b) The increased downward and backward rotation of the mandible is the highest sharing skeletal variable. Thus altering the mandibular plane is recommended during either orthopedic growth modification or orthognathic surgery.

c) The reverse curve of Spee and the proclination of the upper incisors are the highest sharing dental factors in open bite malocclusion.

d) Extraction mechanics in the treatment of open bite would be beneficial to level the curve of Spee together with normalizing the proclined upper incisors

e) The process of treatment planning of open bite should be case based and should be tailored according to the underlying components.

\section{References}

1. Ng CS, Wong WK, Hagg U (2008) Orthodontic treatment of anterior open bite. Int $J$ Paediatr Dent 18: 78-83. [Crossref]
2. Proffit WR, Fields HW Jr, Moray LJ (1998) Prevalence of malocclusion and orthodontic treatment need in the United States: estimates from the NHANES III survey. Int J Adult Orthodon Orthognath Surg 13: 97-106. [Crossref]

3. El-Dawlatly MM, Fayed MM, Mostafa YA (2012) Deep overbite malocclusion: analysis of the underlying components. Am J Orthod Dentofacial Orthop 142: 473 480. [Crossref]

4. Gurton AU, Akin E, Karacay S (2004) Initial intrusion of the molars in the treatment of anterior open bite malocclusions in growing patients. Angle Orthod 74: 454-464. [Crossref]

5. Huang GJ, Drangsholt M (2001) Stability of anterior open bite correction with MEAW Am J Orthod Dentofacial Orthop 119: 14A. [Crossref]

6. Erverdi N, Keles A, Nanda R (2004) The use of skeletal anchorage in open bite treatment: a cephalometric evaluation. Angle Orthod 74: 381-390. [Crossref]

7. Sherwood KH, Burch JG, Thompson WJ (2002) Closing anterior open bites by intruding molars with titanium miniplate anchorage. Am J Orthod Dentofacial Orthop 122: 593-600. [Crossref]

8. Kuroda S, Sakai Y, Tamamura N, Deguchi T, Takano-Yamamoto T (2007) Treatment of severe anterior open bite with skeletal anchorage in adults: comparison with orthognathic surgery outcomes. Am J Orthod Dentofacial Orthop 132: 599-605. [Crossref]

9. Beane RA, Reimann G, Phillips C, Tulloch C (2003) A cephalometric comparison of black open-bite subjects and black normals. Angle Orthod 73: 294-300. [Crossref]

10. Ellis E 3rd, McNamara JA Jr (1984) Components of adult Class III malocclusion. $J$ Oral Maxillofac Surg 42: 295-305. [Crossref]

11. Ellis E 3rd, McNamara JA Jr, Lawrence TM (1985) Components of adult Class II openbite malocclusion. J Oral Maxillofac Surg 43: 92-105. [Crossref]

12. Arat ZM, Akcam MO, Esenlik E, Arat FE (2008) Inconsistencies in the differential diagnosis of open bite. Angle Orthod 78: 415-420. [Crossref]

13. Nanda SK (1990) Growth patterns in subjects with long and short faces. Am J Orthod Dentofacial Orthop 98: 247-258. [Crossref]

14. Sangcharearn Y, Ho C (2007) Effect of Incisor Angulation on Overjet and Overbite in Class II Camouflage Treatment. A typodont study. Angle Orthod 77: 1011-1018. [Crossref]

15. Garlington M, Logan LR (1990) Vertical changes in high mandibular plane case following enucleation of second premolars. Angle Orthod 60: 263-267. [Crossref]

16. Lee HA, Park YC (2008) Treatment and post-treatment changes following intrusion of maxillary posterior teeth with miniscrew implants for open bite correction. Korean $J$ Orthod 38: 31-40.

17. Ng J, Major PW, Flores-Mir C (2006) True molar intrusion attained during orthodontic treatment: a systematic review. Am J Orthod Dentofacial Orthop 130: 709-714. [Crossref]

18. Marshall SD, Caspersen M, Hardinger RR, Franciscus RG, Aquilino SA, et al. (2008) Development of the curve of Spee. Am J Orthod Dentofacial Orthop 134: 344-352. [Crossref]

Copyright: (C2015 El-Dawlatly MM. This is an open-access article distributed under the terms of the Creative Commons Attribution License, which permits unrestricted use, distribution, and reproduction in any medium, provided the original author and source are credited. 